\title{
A multicriteria approach for analysis of the impact of GHG limiting policies on economic growth in Poland
}

\author{
Jan Gadomski ${ }^{1 *}$, Lech Kruś ${ }^{1}$, and Zbigniew Nahorski ${ }^{1,2}$ \\ ${ }^{1}$ Systems Research Institute, Polish Academy of Sciences \\ ${ }^{2}$ Warsaw School of Information Technology
}

\begin{abstract}
The paper deals with the following questions: How to best proceed with a process of the macroeconomic transformation of a medium-size European country due to adjustment of its economy to the EU policy aimed at reducing $\mathrm{CO}_{2}$ emission? What may be the consequences of the enforced emission limits for the economic development and future consumption? To answer these questions a computer-based system has been constructed including a macroeconomic model and a multicriteria optimization tool for two opposing objectives: maximization of the consumption and minimization of the greenhouse gases (GHG) emission. The model contains four production sectors with a special attention devoted to the energy sector, where four technologies are distinguished: the traditional, the modernized traditional and nuclear energy, and the renewable one. The model is the long-horizon one and describes equilibrium trajectories. The multicriteria optimization tool is developed using the reference point approach to support interactive analysis of Pareto optimal outcomes. Computational results are presented for the case of Poland. The welfare costs of the pursuing GHG limiting policy are assessed. Trajectories of the technological changes in time to achieve required limits of $\mathrm{CO}_{2}$ emission are computed.
\end{abstract}

\section{Introduction}

Analysis presented in this paper merges two viewpoints: the technological and economic one. Limiting of the emissions of the greenhouse gases (GHG) aims at preventing the climate warming while the welfare/consumption of people is a common goal of the economic policy. Both goals are strongly intertwined. To a certain extent they are both complementary and substitutes. Decreased GHG emissions can be achieved by choosing less polluting technologies and/or lower output while larger consumption can be attained by increase of the output. Larger consumption can be also achieved by lowering the prices; however, we assume

* Corresponding author: jan.gadomski@ibspan.waw.pl 
in the sequel that the modelling is performed with constant prices Therefore, these goals are contradictory. Aim of the analysis is to assess the consequences of curbing gaseous emissions for the choice of the production technologies and the level of welfare of the population.

Most analyses concerning these issues are performed using computable general equilibrium (CGE) models. In the Polish case the examples of such papers are: Antoszewski [1], Boratyński [2], Roberts [3]. Although very useful and popular, CGE models are based on the concept of equilibria of all markets with prices clearing these markets, and that all economic agents (producers and consumers) maximize their utility functions: profits and consumption respectively. Note that such an approach means microeconomic rationality in given policy framework (taxes, interest rates, etc.). These models often do not account for an impact of monopolies, common in some sectors, on the behaviour of the firms.

In our paper the approach is different. We analyse the effects of macroeconomic policy under the assumption that macroeconomic policy is performed optimally, while there are equilibria on all markets where the prices adjust with some inertia. In the analysis we use macroeconomic multicriteria optimization model [4], based on the earlier version [5], with two criteria: maximization of consumption and minimization of GHG emissions over the optimization period. Decisions concerning amounts of the output, choice of the production technologies and the trade exchange with abroad are found in the optimization process. Similarity in both approaches can be noticed. However, our approach is not considered as a substitute to CGE models but as their complementarity.

The paper is divided into four sections. In the next section the macroeconomic optimization model of Polish economy is presented and the two criteria methodology is outlined. The third section contains description of the simulation experiments. The final section concludes.

\section{Method of analysis}

In our analysis we use macroeconomic optimization model consisting of four production sectors, foreign exchange sector and the consuming sector containing both households as and the public sector. The novelty of the model used in this analysis is twofold: (i) time lags between investments and actual increment of the production capacities, and (ii) additional constraint requiring zeroing of the foreign debt/assets after predetermined time, are added.

The following production sectors are distinguished: the energy sector E (producing energy), the material sector $\mathrm{M}$ (producing non-energy intermediary goods), the consumption goods $\mathrm{C}$ (producing goods that are used up by the consuming sector consisting of households and the public sector), and the investment goods sector I (producing capital/investment goods used by all production sectors). Output of all production sectors can be exported or supported by imports. Output of the sector $\mathrm{E}$ is consumed by all sectors, output of the sector $\mathrm{M}$ is consumed by all production sectors, output of the sector $\mathrm{C}$ is consumed by the consuming sector, and the output of the sector I is used for building production capacities in all production sectors. All production sectors, except for the energy sector, can use two production technologies, and the energy sector has three technologies at disposal. These technologies are interpreted as the traditional fossil fuel, in Poland mainly coal generated energy, mix of the modernized coal generated and nuclear energy, and renewable energy respectively.

Parameters of production technologies in all sectors are distinguished using the following set of indices for the sectors, $\mathrm{i}=\mathrm{E}, \mathrm{M}, \mathrm{C}, \mathrm{I}$; for the technologies, $\mathrm{j}=1,2,3$; and for the years, $\mathrm{t}=1, \ldots, \mathrm{T}$ : 
$\gamma_{i j t}$ - productivity of fixed assets in year $\mathrm{t}$ in $\mathrm{i}$-th sector and $\mathrm{j}$-th technology, it is assumed that in the long term the technical progress increases the productivity of the fixed assets in each year by a constant ratio $r_{\gamma}$ :

$$
\gamma_{i j t}=\gamma_{i j t_{0}}\left(1+r_{\gamma}\right)^{t-t_{0}}
$$

where $\gamma_{i j t_{0}}$ denotes productivity of the fixed assets in year $t_{0}$;

$\delta_{i j}$ - depreciation rate of the fixed assets in i-th sector and $\mathrm{j}$-th technology;

$\alpha_{i j}$ - use of the goods produced in sector $\mathrm{M}$ in producing the unit of the gross product of $\mathrm{i}$-th sector and $\mathrm{j}$-th technology;

$\beta_{i j}$ - use of goods produced in sector $\mathrm{E}$ in producing the unit of the gross product of $\mathrm{i}$-th sector and $\mathrm{j}$-th technology;

$\mu_{i j t}$ - emission per unit in producing the gross product of $\mathrm{i}$-th sector and $\mathrm{j}$-th technology in year $t$, it is assumed that in the long term the technical progress decreases the unit emission in each year by a constant ratio $r_{\mu}$ :

$$
\mu_{i j t}=\mu_{i j t_{0}}\left(1+r_{\mu}\right)^{t-t_{0}}
$$

where $\mu_{i j t_{0}}$ denotes unit emission in year $t_{0}$, while $r_{\mu}$ denotes the rate of the decrease of the emission unit;

$\tau_{i j}$ - duration of the investment process in years (natural number).

Production capacity defined as the potential gross output $Q_{i j t}$ of sector i, i=E, M, C, I; using $\mathrm{j}$-th technology, $\mathrm{j}=1,2,3$; in year $\mathrm{t}, \mathrm{t}=1, . ., \mathrm{T}$; is described by the following one factor production function:

$$
Q_{i j t}=\gamma_{i j t} K_{i j t-1},
$$

where $K_{i j t}$ stands for the stock of the fixed assets in $i$-th sector and $j$-th technology at the beginning of year $t$. In this paper, the potential gross output (3) is also called the production capacity of $j$-th technology in sector E in year $t$.

Actual gross output $X_{i j t}$ cannot exceed the production capacity

$$
\varphi_{i j t} X_{i j t}=Q_{i j t}, \quad \mathrm{j}=1,2,3 ; \mathrm{t}=1, . ., \mathrm{T},
$$

where $\varphi_{i j t}$ stands for the coefficient of the production capacity utilization in $\mathrm{i}$-th sector, $\mathrm{i}=\mathrm{E}$, $\mathrm{M}, \mathrm{C}, \mathrm{I}$; using $\mathrm{j}$-th technology, $\mathrm{j}=1,2,3$; in year $\mathrm{t}$, assuming values from the range $[0 ; 1]$. (In particular, $\varphi_{i j t}=0$ indicates fully idle capital and $\varphi_{i j t}=1$ represents full utilization of the production capacity of $j$-th technology in $i$-th sector in the year $\mathrm{t}$ ).

Total actual output of $i$-th sector, $i=E, M, C, I$; is the sum of outputs produced using available technologies:

$$
X_{i t}=X_{i 1 t}+X_{i 2 t}+X_{i 3 t}, \quad \mathrm{t}=1, . ., T .
$$

Stock of the fixed assets $K_{i j t}$ using $j$-th technology, $j=1,2,3$; in $i$-th sector, $i=E, M, C$, $I$; at the end of year $t$ is given by the relationship:

$$
K_{i j t}=K_{i j t-1}\left(1-\delta_{i j}\right)+I_{i j\left(t-\tau_{i j}\right)}, \quad j=1,2,3 ; t=1, . ., T,
$$

where $I_{i j t}$ denotes investment in $j$-th technology, $j=1,2,3$; in $i$-th sector, $i=\mathrm{E}, \mathrm{M}, \mathrm{C}$, I; in year $t$. (Note that the term $K_{i j t-1} \delta_{i j}$ denotes depreciation of the capital in $i$-th sector and $\mathrm{j}$-th technology). For simplicity lag equal $\tau_{i j}$ years between the investment and its contribution to the stock of fixed assets is assumed.

Production of $i$-th sector using $j$-th technology in year $t$ causes the emissions $S_{i j t}$ of GHG: 


$$
S_{i j t}=\mu_{i j t} X_{i j t} \quad i=\mathrm{E}, \mathrm{M}, \mathrm{C}, \mathrm{I} ; j=1,2 ; t=1, \ldots, T .
$$

The total emission of GHG by $i$-th sector in year $t$ equals:

$$
S_{i t}=S_{i 1 t}+S_{i 2 t}+S_{i 3 t}, \quad i=E, M, C, I ; t=1, . ., T .
$$

Gross income $G I_{t}$ is defined as the sum of incomes generated in sectors E, M, C and $I$ :

$$
\begin{aligned}
G I_{t} & =\left[1-\left(\alpha_{E 1}+\beta_{E 1}\right)\right] X_{E 1 t}+\left[1-\left(\alpha_{E 2}+\beta_{E 2}\right)\right] X_{E 2 t}+\left[1-\left(\alpha_{E 3}+\beta_{E 3}\right)\right] X_{E 3 t}+ \\
& +\left[1-\left(\alpha_{M 1}+\beta_{M 1}\right)\right] X_{M 1 t}+\left[1-\left(\alpha_{M 2}+\beta_{M 2}\right)\right] X_{M 2 t}+ \\
& +\left[1-\left(\alpha_{C 1}+\beta_{C 1}\right)\right] X_{C 1 t}+\left[1-\left(\alpha_{C 2}+\beta_{C 2}\right)\right] X_{C 2 t}+\left[1-\left(\alpha_{I 1}+\beta_{I 1}\right)\right] X_{I 1 t}+\left[1-\left(\alpha_{I 2}+\beta_{I 2}\right)\right] X_{I 2 t}
\end{aligned}
$$

Each year the country is endowed with certain number $N_{t}$ of the emission allowances and its trajectory is determined by the following relationship:

$$
N_{t}=f_{N}\left(t, N_{t_{d}}\right) \quad t=1, . ., T
$$

where $N_{t_{d}}$ denotes the number of the emission allowances in the last considered period.

Disposable income $D I_{t}$ equals the defined above gross income $G I_{t}$, decreased/increased by the debt servicing/income from the foreign assets:

where:

$$
D I_{t}=G I_{t}-r \cdot D_{t-1}+P_{t}\left(N_{t}-S_{t}\right)
$$

$r \quad$ - is the interest rate;

$D_{t} \quad$ - is the foreign debt (if positive) / foreign assets (if negative) at the end of year $t$ :

$$
D_{t}=D_{t-1}-\left(F_{E t}+F_{M t}+F_{C t}+F_{I t}\right),
$$

and $P_{t}$ stands for the price of the emission allowance, $N_{t}$ denotes the number of the emission allowances in year $t$, defined above, $F_{i t} i=\mathrm{E}, \mathrm{M}, \mathrm{C}, \mathrm{I} ; t=1, . ., T$; denotes the foreign trade balance (export-import) in year $t$ of $i$-th sector, and $S_{t}$ denotes the actual total emission:

$$
S_{t}=S_{E t}+S_{M t}+S_{C t}+S_{I t} \text {. }
$$

Equality constraints of the optimization model consist of the balance equations. The left hand sides of these equations denote domestic supply and the right hand sides represent domestic demand supplemented by the balances of foreign exchange of the given good.

The balance equation of $\mathrm{E}$ sector is expressed by the following equation:

$$
\begin{aligned}
X_{E 1 t}+X_{E 2 t}+X_{E 3 t}= & \beta_{E 1 t} X_{E 1 t}+\beta_{E 2 t} X_{E 2 t}+\beta_{E 3 t} X_{E 3 t}+\beta_{M 1 t} X_{M 1 t}+\beta_{M 2 t} X_{E 2 t}+ \\
& +\beta_{C 1 t} X_{C 1 t}+\beta_{C 2 t} X_{C 2 t}+\beta_{I 1 t} X_{I 1 t}+\beta_{I 2 t} X_{I 2 t}+\rho_{t} \lambda D I_{t}+F_{E t},
\end{aligned}
$$

where the term

$$
\begin{aligned}
\beta_{E 1 t} X_{E 1 t}+\beta_{E 2 t} X_{E 2 t}+\beta_{E 3 t} X_{E 3 t}+\beta_{M 1 t} & X_{M 1 t}+\beta_{M 2 t} X_{M 2 t}+ \\
& +\beta_{C 1 t} X_{C 1 t}+\beta_{C 2 t} X_{C 2 t}+\beta_{I 1 t} X_{I 1 t}+\beta_{I 2 t} X_{I 2 t}
\end{aligned}
$$

denotes consumption of energy in year $t$ in sectors M, E, C, I; using all technologies available in those sectors, and the term $F_{E t}$ stands for the net balance of the foreign trade of the sector $E$ (if $E X P_{E t}-I M P_{E t}=F_{E t} \geq 0$, then export $E X P_{E t}$ exceeds import $I M P_{E t}$ in the foreign trade of goods produced by the sector E; and if $F_{E t}<0$, then import $I M P_{E t}$ exceeds export $E X P_{E t}$ in the foreign trade in energy). The term $\rho_{t} D I_{t}, 0<\rho_{t} \leq 1$, denotes consumption, or part of the disposable income $D I_{t}$ in the year $t$ designed for the purchases of the consumption goods, of which $\lambda \rho_{t} D I_{t}$ stands for the part of the total consumption expenditures directed for 
the purchases of energy. Note that the part $\left(1-\rho_{t}\right) D I_{t}$ of the disposable income equals the total investment expenditures. Coefficient $\rho_{t}$ is not a constant as it depends on the propensity to invest. Constant coefficient $\lambda, 0<\lambda \leq 1$, denotes assumed constant share of the energy expenditures in the total consumption expenditures.

Supply of goods produced by sector $M$ is supplemented by import, while some part of its output can be directed to export. The gross output of sector $M$ is distributed in the way expressed by the following balance equation:

$$
\begin{aligned}
X_{M t} & =\alpha_{M 1} X_{M 1 t}+\alpha_{M 2} X_{M 2 t}+\alpha_{E 1} X_{E 1 t}+\alpha_{E 2} X_{E 2 t}+\alpha_{E 3 t} X_{E 3 t}+\quad t=1, . ., T ; \\
& +\alpha_{C 1} X_{C 1 t}+\alpha_{C 2} X_{C 2 t}+\alpha_{I 1} X_{I 1 t}+\alpha_{I 2} X_{I 2 t}+F_{M t},
\end{aligned}
$$

where the term

$$
\alpha_{M 1} X_{M 1 t}+\alpha_{M 2} X_{M 2 t}+\alpha_{E 1} X_{E 1 t}+\alpha_{E 2} X_{E 2 t}+\alpha_{E 3 t} X_{E 3 t}+\alpha_{C 1} X_{C 1 t}+\alpha_{C 2} X_{C 2 t}+\alpha_{I 1} X_{I 1 t}+\alpha_{I 2} X_{I 2 t}
$$

denotes consumption of the non-energy intermediate inputs in year $t$ in sectors M, E, C, I, and $F_{M t}$ stands for the net balance of the foreign trade of sector $\mathrm{M}\left(E X P_{M t}-I M P_{M t}=F_{M t} \geq 0\right.$ means that export $E X P_{M t}$ exceeds import $I M P_{M t}$ in the foreign trade of goods produced by the sector M, and opposite when $F_{M t}<0$ ).

Supply of goods produced by sector I is supplemented by the import, while some part of its output can be directed to export. The gross output of sector I is distributed as described by the following balance equation:

$$
X_{I t}=I_{t}+F_{I t}, \quad t=1, . ., T ;
$$

where the term $I_{t}$

$$
I_{t}=\left(1-\rho_{t}\right) D I_{t}=I_{M 1 t}+I_{M 2 t}+I_{E 1 t}+I_{E 2 t}+I_{E 3 t}+I_{C 1 t}+I_{C 2 t}+I_{I 1 t}+I_{I 2 t}
$$

denotes total investment in sectors $\mathrm{M}, \mathrm{E}, \mathrm{C}, \mathrm{I}$, and all technologies in year $t$, and $F_{I t}$ stands for the net balance of the foreign trade of sector I (if $E X P_{I t}-I M P_{I t}=F_{I t} \geq 0$, the export $E X P_{I t}$ exceeds the import $I M P_{I t}$ in the foreign trade of goods produced by sector I, and opposite if $\left.F_{I t}<0\right)$.

Supply of goods produced by sector $C$ is supplemented by the import, while some part of its output can be directed to the export. The balance equation of sector $C$ is as follows:

$$
X_{C t}=\rho_{t} \cdot(1-\lambda) \cdot D I_{t}+F_{C t},
$$

showing that the domestic supply (left-hand side of the above equation) of the non-energy consumption goods is equal to the demand generated by the part of the disposable income directed at purchasing non-energy consumption goods and the balance of the foreign trade in those goods (right hand side of the equation (20)). It is worth noting that the variable $\rho_{t}$ can be interpreted as the propensity to consume. The term $F_{C t}$ stands for the net balance of the foreign trade of sector $\mathrm{C}$ (if $E X P_{C t}-I M P_{C t}=F_{C t} \geq 0$, export $E X P_{C t}$ exceeds import $I M P_{C t}$ in the foreign trade of goods produced by sector $\mathrm{C}$, and opposite if $F_{C t}<0$ ).

Households and the public sector belong to the same sector called the consuming sector, where decisions being made concern the following factors: utilization of the production capacities in the sectors and technologies; distribution of the disposable income between the consumption and investment; technology choice; and the role of the foreign trade. Constant proportion between the household and public consumption is assumed.

Decision variables in the model include: the actual gross outputs in the sectors and technologies; investment in the capital assets in the sectors and technologies; and the foreign trade balances of all production sectors: 


$$
\begin{aligned}
& X_{E 1 t}, X_{E 2 t}, X_{E 3 t}, X_{M 1 t}, X_{M 2 t} X_{C 1 t}, X_{C 2 t} X_{I 1 t}, X_{I 2 t}, I_{E 1 t}, I_{E 2 t}, I_{E 3 t}, I_{M 1 t}, I_{M 2 t} I_{C 1 t}, I_{C 2 t} I_{I 1 t}, I_{I 2 t}, \\
& F_{E t}, F_{M t}, F_{C t}, F_{I t}, N_{t_{d}} .
\end{aligned}
$$

The inequality constraints are as follows.

Non-negative outputs and investments (foreign trade balances $F_{E t}, F_{M t}, F_{C t}, F_{I t}$ can be either positive or negative):

$$
X_{E 1 t}, X_{E 2 t}, X_{E 3 t}, X_{M 1 t}, X_{M 2 t} X_{C 1 t}, X_{C 2 t} X_{I 1 t}, X_{I 2 t}, I_{E 1 t}, I_{E 2 t}, I_{E 3 t}, I_{M 1 t}, I_{M 2 t} I_{C 1 t}, I_{C 2 t} I_{I 1 t}, I_{I 2 t} \geq 0 .
$$

Propensity to invest, defined as a ratio $I_{t} / D I_{t}$ that cannot exceed the maximum propensity to invest:

$$
I_{t} / D I_{t} \leq \sigma_{I / D I}
$$

where $\sigma_{I / D I}$ denotes the maximum value of the investment to the income ratio.

The above constraint reflects social resistance to the exceedingly high propensity to invest. The propensity to consume $\rho_{t}$ is also constrained from beneath:

$$
\rho_{t} \geq \sigma_{\text {cons } / D I}
$$

where coefficient $\sigma_{\text {cons } / D I}$ denotes the minimum value of the consumption to the income ratio.

Another set of constraints deals with the feasible shares of the foreign trade in the sector outputs. The following constraints:

$$
\begin{array}{rlrl}
\sigma_{I M P / X} \leq \frac{I M P_{t}}{X_{t}} \leq \sigma_{I M P / X} & j=\mathrm{M}, \mathrm{E}, \mathrm{C}, \mathrm{I} ; \\
\sigma_{E X P / X} \leq \frac{E X P_{t}}{X_{t}} \leq \sigma_{E X P / X} & j=\mathrm{M}, \mathrm{E}, \mathrm{C}, \mathrm{I} ;
\end{array}
$$

impose the maximum proportion of the import and export, respectively, in the national supply of the given product, where coefficients $\sigma_{I M P / X}$ and $\sigma_{E X P / X}, j=\mathrm{M}, \mathrm{E}, \mathrm{C}$, I; denote, respectively, the maximum ratio of the import and export of a given product to its national gross output.

The following two constraints:

$$
\begin{aligned}
& -r_{I N V}^{(-)} \leq \frac{I_{i j t}-I_{i j t-1}}{I_{i j t-1}} \leq r_{I N V}^{(+)}, \quad j=1,2,3 ; j=\mathrm{M}, \mathrm{E}, \mathrm{C}, \mathrm{I} ; \\
& -r_{\text {cons }}^{(-)} \leq \frac{\rho_{t} D I_{t}-\rho_{t-1} D I_{t-1}}{\rho_{t-1} D I_{t-1}} \leq r_{\text {cons }}^{(+)},
\end{aligned}
$$

limit relative increases and decreases of investments in the sectors and the total consumption, respectively, where parameters $r_{N V i j}^{(-)}$and $r_{N V i j}^{(+)}$stand for the lowest and highest admissible rates of increase of the investment in technology $j, j=1,2,3 ; i=\mathrm{M}, \mathrm{E}, \mathrm{C}, \mathrm{I}$; while $r_{\text {cons }}^{(-)}$and $r_{\text {cons }}^{(+)}$ denote the lowest and highest admissible rates of the consumption change, respectively. In particular, the constraint (28) reflects the social sensitivity to the changes in consumption and a possible resistance to them.

The following constraint reflects policy decisions concerning the desired share of a certain technology in the total output of a certain sector. In the current version of the model this constraint is the consequence of the requirement that in the energy sector the share of the renewable technology should be at least equal to $20 \%$, beginning from the year 2030 :

$$
\frac{X_{E 3 t}}{X_{E 1 t}+X_{E 2 t}+X_{E 3 t}} \geq 20 \% ; t \geq 2030 \text {. }
$$

The following constraint limits the possibility of the excessive debt/credit as relative to the gross income 


$$
-0.60 \cdot G I_{t} \leq D_{t} \leq 0.60 \cdot G I_{t} .
$$

The last constraint determines the policy time limit $t_{F}$ of using the foreign debt / foreign assets as investment in of the means supporting technology conversion:

$$
D_{t}=0, \quad t>t_{F}
$$

Two opposing criteria of macroeconomic development are considered:

$$
\text { maximization of the long-run consumption: } \quad \max \sum_{t=t_{0}}^{T} \rho_{t} D I_{t}\left(1+r_{d}\right)^{-\left(t-t_{0}\right)} \text {, }
$$

minimization of the emission allowances in the final year $t_{d}$ : $\quad N_{t_{d}}$,

The former is the present value of consumption (discounted consumption over the simulation period) and the latter is the cumulative emission over the simulation period.

Decrease of GHG emissions is implemented by allotting to a country a prenegotiated diminishing number of the emission allowances that should be met in a given time period. In this study, a linear-wise pathway of emission allowance limits is assumed. The pathway trajectories are formed by joining values of emission allowance limits in the initial year, in the intermediate years, and in the destination year, Figure 1. The actual GHG emission time trajectory in our study can however differ from the assumed pathway, due to allowed trade of the allowances.

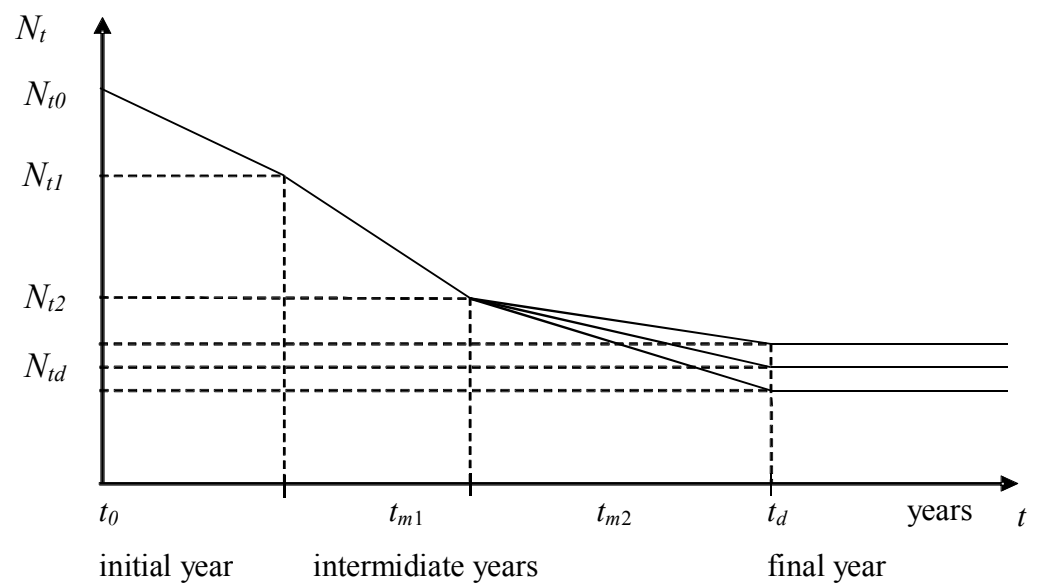

Fig. 1 Assumed emission allowance pathway trajectories. $t_{0}=2010, t_{m 1}=2020, t_{m 2}=2030, t_{d}=2050$.

The initial year $t_{0}$ chosen in this study is 2010. The numbers of the emission allowances $N_{t_{0}}$ in the initial year and in the intermediate years are defined according to the EC agreements. The number of the allowances in the destination year 2050 is a variable that can be negotiated and is treated as a criterion considered together with the discounted consumption criterion. The multicriteria analysis is applied, with two criteria. The first, which is the discounted consumption that represents effects of the economic growth of the country, is maximized. The second, which is the number of the allowances in the destination year representing the emission curbing EC policy, is minimized.

As the model relations include only the affine expressions (1) - (31), they can be described in the form $A x \leq b$, where $x$ is the vector of the decision variables, $A$ is the matrix and $b$ is the vector of the coefficients. The vector $x$ - see expression (21), includes the decision variables, which are non-negative, according to the assumption (22). 
Denote by $y(x)=\left[y_{1}(x), y_{2}(x)\right]$ the vector of the criteria, where $y_{1}$ is the discounted consumption (32), and $y_{2}$ is the number of the emission allowances in the destination year $t_{d}$. Due to the affine model relations, the criteria $y_{\mathrm{i}}, i=1,2$, can be expressed as $y_{i}=c_{i}^{T} \cdot x+d_{i}$ ,where $\boldsymbol{c}_{\boldsymbol{i}}, \boldsymbol{d}_{\boldsymbol{i}}, i=1,2$ are vectors of coefficients. The criteria are conflicting. That is why the multicriteria optimization is applied, in which the decision variables that satisfy the constraints and jointly maximize $y_{1}$ and minimize $y_{2}$ are looked for. The problem is considered in two spaces, that of the decision variables, and that of the criteria. The model constraints define the set $\mathbf{X}_{0}$ of admissible values of the decision variables in the first space. In the second two-dimensional space there exists the set $\mathbf{Y}$ of attainable values of the criteria (outcomes). Decision variables leading to the nondominated (Pareto optimal) points in the set $\mathbf{Y}$ are looked for. We introduce the following domination relation in the space $\mathbf{R}^{2}$ of criteria $\left(y_{1}, y_{2}\right)$. A vector $y=\left(y_{1}, y_{2}\right)$ dominates a vector $v=\left(v_{1}, v_{2}\right)$, where $y, v \in \mathbf{R}^{2}$, if $y_{1} \geq v_{1}$ $\wedge y_{2} \leq v_{2} \wedge y \neq v$. A vector $y=\left(y_{1}, y_{2}\right)$ strictly dominates a vector $v=\left(v_{1}, v_{2}\right)$, if $y_{1}>v_{1} \wedge y_{2}<v_{2}$. The domination relation defines partial ordering in the criteria space, which is not a linear one. So, in this case the traditional optimality concept defined for one criterion is not valid. A vector $y^{p}$ is Pareto optimal (nondominated) in the set $\mathbf{Y}_{0}$, if $y^{p} \in \mathbf{Y}$ and there is no vector $v \in \mathbf{Y}$ dominating the vector $y^{p}$. A vector $y^{p s}$ is weakly Pareto optimal (weakly nondominated) in the set $\mathbf{Y}$, if $y^{p s} \in \mathbf{Y}$ and there is no vector $v \in \mathbf{Y}$ strictly dominating the vector $y^{p s}$. In the case analysed here the set $\mathbf{Y}$ is not given explicitly. Particular points of the set can be only found by computer simulations. The set of decision variables in $\mathbf{X}_{0}$ that corresponds to the set of the Pareto optimal points in $\mathbf{Y}$ is derived and analysed.

The multicriteria optimization problem is solved using the reference point approach with an order achievement function, developed by Wierzbicki [8], [9]. The elaborated computer system generates the Pareto optimal solutions in an interactive way. Assuming and assigning different reference values for the criteria and solving the resulting optimization problems, different Pareto optimal outcomes and decision variables are derived, compared and analyzed. For this, the order approximation achievement functions is used. In this approach, some reference points in the criteria space are given by a system analyst and then the computer-based system generates corresponding outcomes which are Pareto optimal in the set of attainable outcomes. This way a representation of the Pareto frontier can be obtained. Outcomes characterizing the Pareto frontier are derived by $\max _{x \in \mathrm{X}_{0}}\left[s\left(y(x), y^{*}\right)\right]$, where: $\mathbf{X}_{0}$ is a set of admissible decisions defined by the model relations, $y^{*}=\left(y_{1}^{*}, y_{2}{ }^{*}\right)$ is a reference (aspiration) point assumed in the criteria space $\mathbf{R}^{2}$, and $s\left(y, y^{*}\right)$ is an order approximating achievement function.

The respective form of the achievement function has been applied and the optimization problem has been transformed to the linear optimization task solved sequentially, like in Gadomski at al. [5].

\section{Simulations}

Results described in this paper were obtained on the basis of the data from Input-output Tables of Poland in 2010 and from other data published in [6]. Unavailable data were estimated and, in some cases, based on the expert opinions. Simulations assumed $1.5 \%$ yearly increases of the productivity of capital in all sectors and technologies, and $1 \%$ yearly decreases of the unit emission in all sectors and technologies. All economic variables are 
expressed in constant prices. It is assumed that the international and national prices maintain fixed proportions.

As motivated earlier, the year 2010 is chosen as the initial year of the simulations. It is assumed that before the initial year the economy has grown along the equilibrium path with a steady growth rate which determined proportions between sectors. The imposed emission pathway disturbs the growth but, after a turbulent transition period of the technology conversion, the economy resumes to grow along the new equilibrium path. Our analysis is focused on the period where most macroeconomic adjustments is performed.

The emission of GHG in Poland in 2010 is related to the emission in 2005, which was equal 353.9 million ton of $\mathrm{CO}_{2}$ eq (Olecka et al. [7]). This value is adopted as a referential number of allowances allotted to Poland. The emission allowance pathway is assumed to have the shape presented in Fig. 1. The assumed numbers of emission allowances in the years 2020 and 2030 are $79 \%$ and $57 \%$, respectively, as related to the their number in 2005 . The number of allowances in the destination year is minimized. The discounted consumption in the full period of time is another criterion that is maximized. For different aspiration points assumed in the space of these two criteria, represented in Fig. 2 by small squares, the optimized nondominated points, represented by small circles, were obtained. Arrows indicate correspondence of the nondominated and the aspiration points, which form a representation of the set of the nondominated outcomes (Pareto frontier) in $\mathbf{Y}$ which is approximated in Fig. 2 by the dashed line. The outcomes located to the left of the Pareto frontier are unattainable, i.e. they do not belong to the set $\mathbf{Y}$.

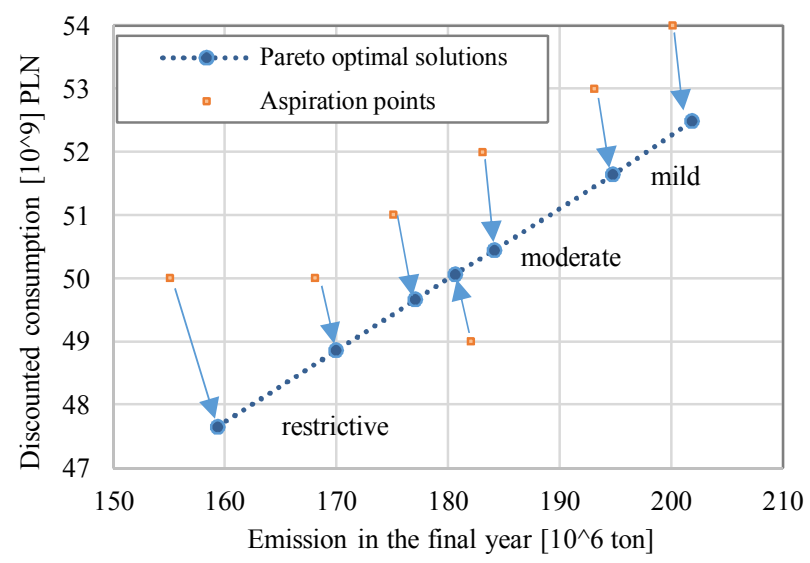

Fig. 2 Results of the interactive multicriteria analysis. The dashed line is an approximation of the Pareto set.

The numerical computed results are presented in Table 1 . The case 8 relates to the maximum possible decrease of the number of the emission allowances in the destination year, for which the lowest feasible consumption constraint (29) is active. It is called the restrictive variant. It is the solution of the single criterion optimization problem with minimization of the emission allowances number in the destination year. It represents the greatest possible decrease of the emission allowances for the destination year within the assumed constraints, which is around $80 \%$ reduction of the Kyoto base emission for Poland. In the case 1, called the mild variant, there is no decrease of the number of emission allowances after the second intermediate year 2030. Among the intermediate points, the case 3 is chosen and called the moderate variant. It relates to a moderate decrease of the number of allowances in the destination year. 
Two variants of the trajectory of numbers of the emission allowances were chosen for presentation: the mild and restrictive one. The former assumes that from year 2030 on the final yearly amount of allowances is equal to $57 \%$ of 2005 emission level and the latter assumes that from year 2050 on the final yearly amount of allowances is equal to $45 \%$ of 2005 emission level, see Fig. 3 (d). Main macroeconomic indicators that are GDP, consumption, investment, and emissions, are presented in Fig. 3.

Table 1. Selected results of the multicriteria analysis

\begin{tabular}{|c|c|c|c|c|c|c|c|c|c|}
\hline & \multicolumn{2}{|c|}{ Aspiration points } & \multicolumn{6}{|c|}{ Pareto optimal solutions } & \multirow[b]{2}{*}{$\begin{array}{c}\text { Cumulated } \\
\text { emission } \\
{\left[10^{\wedge} 6\right] \text { ton }}\end{array}$} \\
\hline Scenario & $\begin{array}{c}\text { Emissin in } \\
\text { the final } \\
\text { year } \\
{\left[10^{\prime} 6 \text { ton }\right]}\end{array}$ & $\begin{array}{l}\text { Discounted } \\
\text { consumption } \\
{\left[10^{\wedge} 9\right] \text { PLN }}\end{array}$ & $\begin{array}{l}\text { Decrease of } \\
\text { emission } \\
\text { compared to } \\
\text { the initial year }\end{array}$ & $\begin{array}{c}\text { Emission in } \\
\text { the final } \\
\text { year }\left[10^{\wedge} 6\right. \\
\text { ton] }\end{array}$ & $\begin{array}{l}\text { Discounted } \\
\text { consumption } \\
{\left[10^{\wedge} 9\right] \text { PLN }}\end{array}$ & $\begin{array}{c}\text { Decrease of } \\
\text { consumption } \\
\text { compared to the } \\
\text { mild scenario } \\
{\left[10^{\wedge} 9\right] \text { PLN }}\end{array}$ & $\begin{array}{l}\text { Decrease of } \\
\text { consumption } \\
\text { compared to } \\
\text { the mild } \\
\text { scenario in \% }\end{array}$ & $\begin{array}{l}\text { Cumulated } \\
\text { consumption } \\
{\left[10^{\wedge} 9\right] \text { PLN }}\end{array}$ & \\
\hline 1 restrictive & 155 & 50.0 & $45 \%$ & 159.3 & 47.7 & 4.83 & $9.20 \%$ & 112.6 & 21909 \\
\hline 2 & 168 & 50.0 & $48 \%$ & 169.9 & 48.9 & 3.62 & $6.90 \%$ & 117.5 & 22869 \\
\hline 3 & 175 & 51.0 & $50 \%$ & 177.0 & 49.7 & 2.82 & $5.36 \%$ & 121.0 & 23509 \\
\hline 4 moderate & 183 & 52.0 & $51 \%$ & 180.5 & 50.1 & 2.41 & $4.60 \%$ & 122.5 & 23829 \\
\hline 5 & 182 & 49.0 & $52 \%$ & 184.1 & 50.5 & 2.04 & $3.89 \%$ & 124.2 & 24149 \\
\hline 6 & 193 & 53.0 & $55 \%$ & 194.7 & 51.7 & 0.84 & $1.60 \%$ & 129.0 & 25130 \\
\hline 7 mild & 200 & 54.0 & $57 \%$ & 201.7 & 52.5 & 0.00 & $0.00 \%$ & 132.1 & 25748 \\
\hline
\end{tabular}
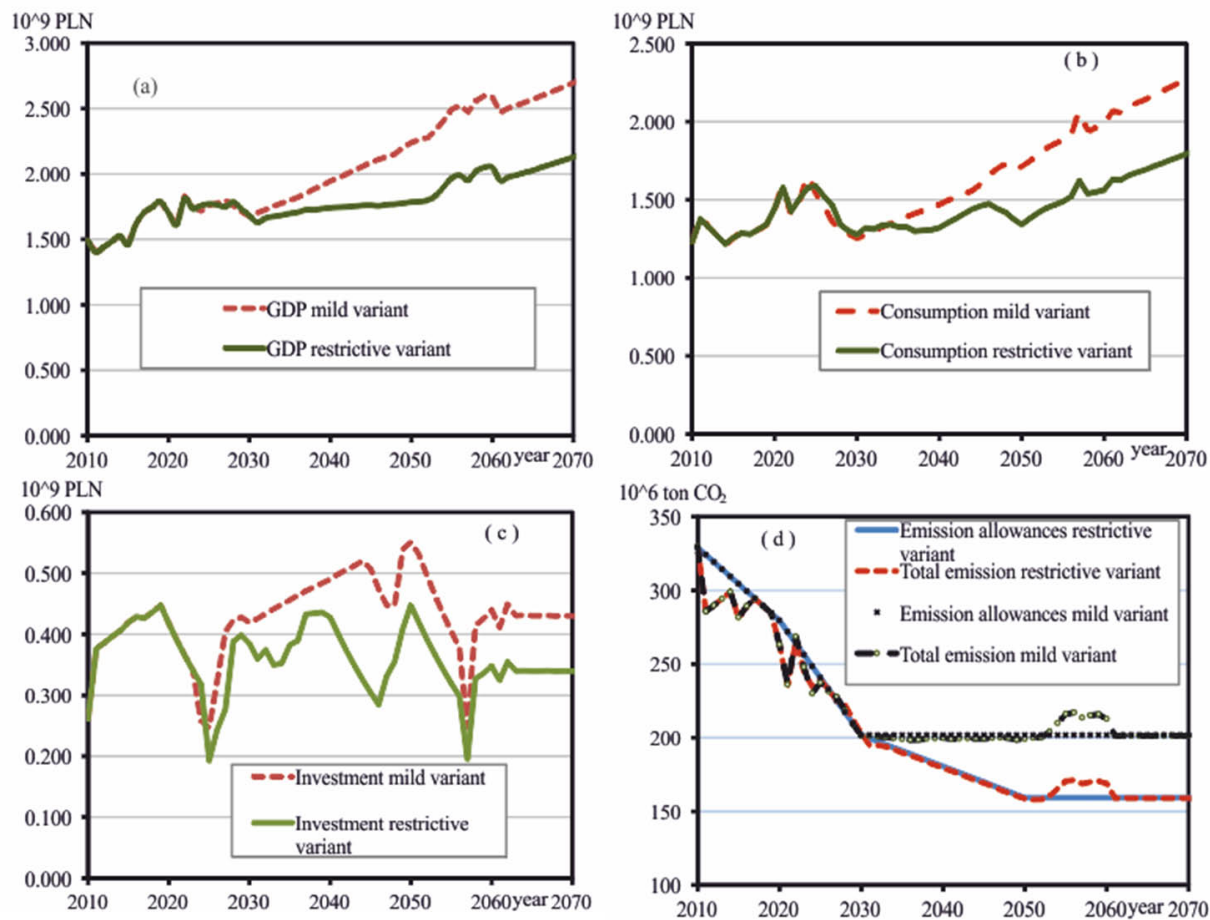

$10^{\wedge} 6$ ton $\mathrm{CO}_{2}$

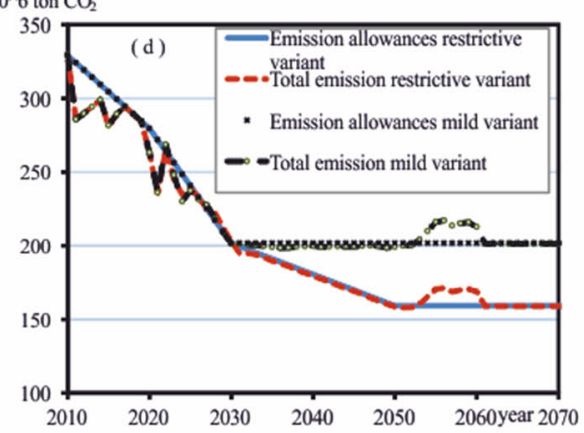

Fig. 3. (a) GDP, (b) consumption, (c) investment and (d) the amounts of the emission allowances and actual emissions in two variants (mild and restrictive) without technical progress.

All simulations have one element in common, namely successful technology conversion requires high market prices of the emission allowances. At low prices this conversion is considerably delayed or does not occur at all. In all sectors the cleanest technologies are employed. Moreover, in the energy sector employment of the modernized traditional 
technology derives from the volatility of the renewable energy sources, which would otherwise dominate.

After initial rise of GDP, consumption and investment, there follows long lasting recession. (Note that both mild and restrictive variants have similar characteristics).

In the initial phase technological conversion causes diminished utilization of the production capacities, the deepest in E sector, followed by $\mathrm{M}$ sector. This drop of the production capacities occurs the latest in sector I, as the burden of the technological change is concentrated there, see left hand panel of the Fig. 4, This phenomenon requires explanation, because it is accompanied by increase of the production capacities only in cleaner technologies. In modelling of the production system we have not taken into account the accelerated depreciation, decommissioning or scrapping of the idle capital assets. Abandoning of a technology results in gradual decrease of the capital assets accordingly with the equation (6). This result indicates that beside the cost of the technology conversion expressed in terms of consumption, there occur also losses related to idle capital assets.

The technological conversion has significant impact on the structure of the national economy. One should notice considerable increase of the share of sector $\mathrm{E}$ in the gross output. As there are negligible differences between the mild and restrictive variants, developments of the production capacities utilization and the shares of particular sectors in the national economy are presented in Fig. 4 using the results of the mild variant. One can conclude that the decreased rate of the production capacity utilization belongs to the cost of technological change. The greatest drop in the production capacities can be observed in the energy sector and the smallest in the investment sector.

Participation in the gross output changes considerably. One can note that the share of the energy sector significantly increases with the expansion of the newer technologies, see right hand panel of Fig. 4.
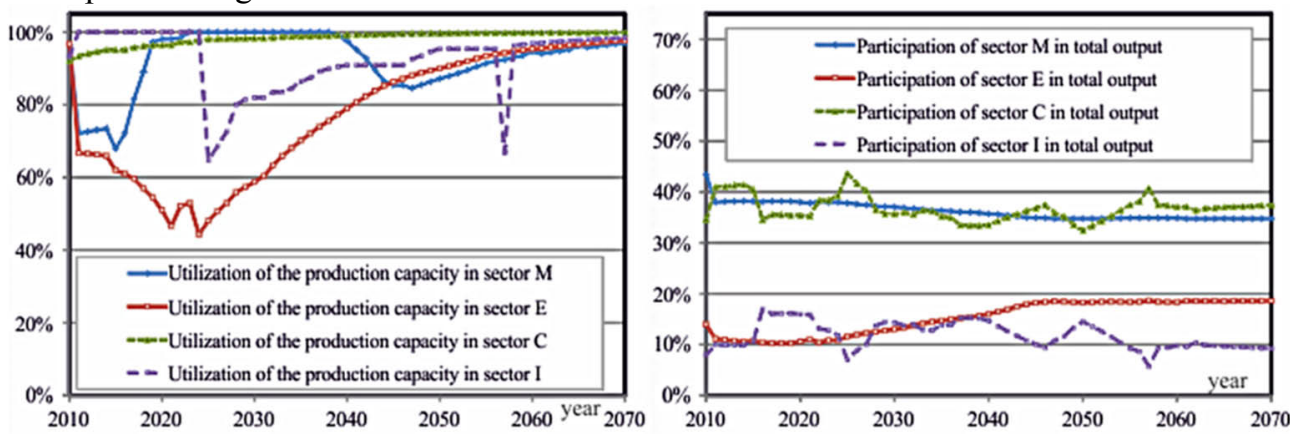

Fig. 4. Production capacities utilization, left hand panel, shares of particular sectors in the national economy, right hand panel.

Performed calculations allow an assessment of the cost of curbing emissions in terms of consumption lost as presented in Fig. 5. 


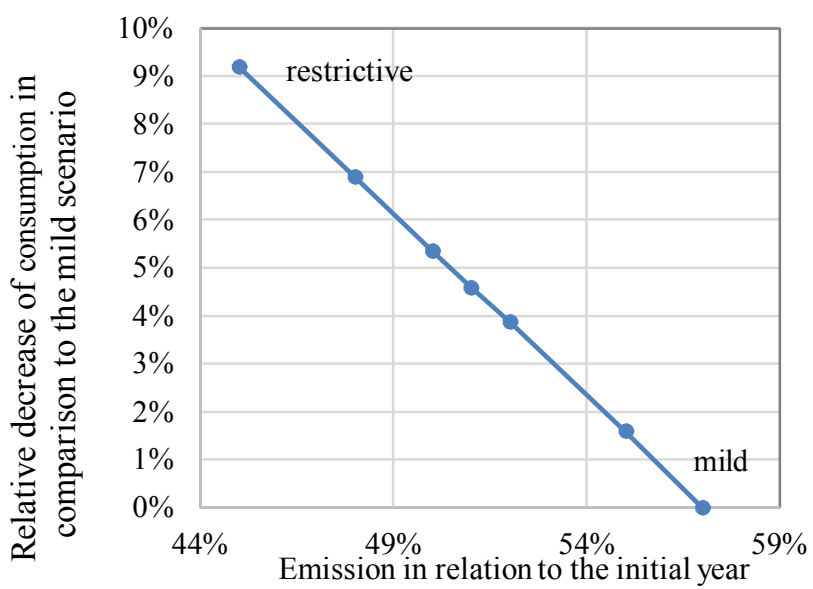

Fig. 5. Losses in consumption due to decreased emission.

\section{Conclusions}

The paper presents a macroeconomic model and multicriteria optimization tool for analysis of the consequences of the enforced emission limits for the economic development in Poland. A special attention is devoted to the energy sector. Different technologies are distinguished in the model, such as the modernized traditional and nuclear, as well as renewable, in comparison to the traditional one. The model determines equilibrium trajectories and makes it possible to analyze different scenarios of the technical progress development.

The applied multicriteria optimization focuses on two contradictory objectives: decreasing GHG emissions, and maintaining the highest possible growth rate. This enables analysis of the trade-off problem between two competing goals: reduction of the GHG emissions with the sustainable economic growth, as well as changes of the sectorial structure of investment and output. Also assessment of the cost of the GHG emission reduction in terms of the consumption lost is done.

The multicriteria optimization approach proved to be effective in analysis of the impacts of enforcing emission limits on the economic development process, and on the economic transformation caused by adjustment of the national economy to the emission decreasing policy. The technological conversion trajectory was derived for seven Pareto optimum solutions. Two solutions (mild and restrictive) are presented and discussed in the paper.

In all sectors but sector I (having negligibly low emissions in both technologies), new technologies replaced old ones in the investment outlays. It is necessary to note that in the energy sector the most expensive technology has been chosen (the one interpreted as the renewable). This can be explained by the severity of the end period emission constraints. However, very high volatility of supply from the energy sector makes problems in modelling and optimization, as its maximum capacity of production is practically never met, in particular in the case of the renewable technology. Considering year production, as in our analysis, the mean production can be predicted with good enough accuracy. But the short time production may vary considerably. Hence, high share of renewable energy requires keeping a large reserve of the traditional non-renewable technology power, which actually is the case in our modelling, or very advanced balancing of energy production and consumption, including energy storage. Therefore the minimum share of the second technology in total energy output has been included as a constraint in the model.

A necessity to adjust to the lowest emission levels at the end-period forces the economic system to cumulate consumption at the beginning period, with the similar impact on 
investment, and GDP, Fig. 3. As a result, the initial period of growth lasts only to 2013 and is followed by recession and then stagnation, both determined by the admissible level of emission.

Results performed by the proposed model confirm its applicability in the analysis of the impact of the policy of curbing the GHG emissions on the growth of the national economy. This model should not be treated as the substitute but as an alternative and a supplementary analytical tool to the more popularly used CGE models. It is important to remember that the results are presented in constant prices, and that an exogenous evolution in prices can be considered given credible scenario to obtain the results in actual prices.

\section{References}

1. M. Antoszewski, J. Boratyński et al., CGE model PLACE, MF Working Paper Series, Ministry of Finance, Republic of Poland, Warsaw (2015).

2. J. Boratyński, Historical simulations with a dynamic CGE model: Results for an emerging economy, Ecomod Conference, Seville. (2012)

3. B. M. Roberts, Calibration procedure and the robustness of CGE models: Simulations with a model for Poland, Economics of Planning, 189-210, Kluwer Academic Publishers (1994).

4. J. Gadomski, Assessment of the impact of the reduction of the gaseous emissions on growth in Poland. Assumptions and preliminary results. Przeglad Statystyczny, 3:237287 (2016).

5. J. Gadomski, L. Kruś, Z. Nahorski, A multicriteria model for analysis of the impact of GHG limiting policies on economic growth. The case of Poland. Systems Research Institute of PAS, Working Paper No RB/37/2014. Warsaw (2014)

6. Central Statistical Office, Republic of Poland, Input-Output Table at Basic Prices in 2010, Warsaw (2011).

7. A, Olecka, K, Bebkiewicz, B. Dębski et al., National Inventory Report 2014. GHG Inventories for Poland for the years 1988-2012. The National Centre of Emission Management, Warsaw (2014) (in Polish)

8. A. P. Wierzbicki, On the completeness and constructiveness of parametric characterizations to vector optimization problems. OR Spectrum 8:73-87 (1986).

9. A. P Wierzbicki, M. Makowski, J. Wessels, Model-based Decision Support Methodology with Environmental Applications. Kluwer Academic Press, Dordrecht, Boston (2000). 